
\title{
25 Research Suare \\ Optimising Malaria Control Interventions in Mali Based on Epidemiological Surveillance and Rainfall Data
}

Cissoko Mady ( $\square$ madycissoko@ymail.com )

SESSTIM UMR 1252 https://orcid.org/0000-0002-0200-8191

Mady CISSOKO

USTTB FMOS: Universite des Sciences des Techniques et des Technologies de Bamako Faculte de Medecine et d'Odontostomatologie

\section{Issaka Sagara}

USTTB FMOS: Universite des Sciences des Techniques et des Technologies de Bamako Faculte de Medecine et d'Odontostomatologie

Jordi Landier

AMU: Aix-Marseille Universite

\section{Abdoulaye Guindo}

USTTB FMOS: Universite des Sciences des Techniques et des Technologies de Bamako Faculte de Medecine et d'Odontostomatologie

\section{Vincent Sanogo}

PNLP Mali

\section{Oumou Yacouba Coulibaly}

DGSPH Mali

\section{Pascal Dembélé}

PNLP Mali

\section{Sohkna Dieng}

Aix-Marseille Universite de Provence: Aix-Marseille Universite

\section{Cedric Batio Stephane}

Aix-Marseille Universite de Provence: Aix-Marseille Universite

\section{Issa Diarra}

USTTB FMOS: Universite des Sciences des Techniques et des Technologies de Bamako Faculte de Medecine et d'Odontostomatologie

\section{Mahamadou H. Magassa}

PNLP Mali

\section{Ibrahima Berthé}

USTTB FMOS: Universite des Sciences des Techniques et des Technologies de Bamako Faculte de Medecine et d'Odontostomatologie

\section{Abdoulaye Katilé}


USTTB FMOS: Universite des Sciences des Techniques et des Technologies de Bamako Faculte de Medecine et d'Odontostomatologie

\section{Diahara Traoré}

PNLP Mali

\section{Nadine Dessay}

ESPACE DEV IRD Monpellier UMR 228

\section{Jean Gaudart}

Aix Marseille Univ, APHM, INSERM, IRD, SESSTIM, ISSPAM, Hop Timone, BiostSTIC, Biostatistic and ICT, 13005 Marseille

\section{Research Article}

Keywords: malaria, high transmission season, rainfall, season, optimisation.

Posted Date: January 10th, 2022

DOI: https://doi.org/10.21203/rs.3.rs-1235012/v1

License: (9) (i) This work is licensed under a Creative Commons Attribution 4.0 International License. Read Full License 


\section{Abstract}

Background In malaria endemic countries, control interventions are performed during the high malaria transmission season using epidemiological surveillance data. One such intervention, seasonal chemoprevention (SMC), consists of the monthly administration of antimalarial drugs to children under 5 years. This study proposes an anticipating approach for adapting the timing of SMC interventions in Mali and the number of rounds. Our primary objective was to select the best approach for anticipating the onset of the high transmission season in the different health districts of Mali based on epidemiological surveillance and rainfall data. Our secondary objective was to evaluate the number of malaria cases, hospitalisations, and deaths in children under 5 years that could be prevented in Mali using the selected approach and the additional cost associated.

Method Confirmed malaria cases and weekly rainfall data were collected for the 75 health districts of Mali for the 2014-2019 period. The onset of the rainy season, the onset of the high transmission season, the lag between these two events and the duration of the high transmission season were determined for each health district. Two approaches for anticipating the onset of the high transmission season in 2019 were evaluated.

Results In 2014-2019, the onset of the rainy season ranged from W17 April to W34 August and that of the high transmission season from W25 June to W40 September. The lag between these two events ranged from 5 to 12 weeks. The duration of the high transmission season ranged from 3 to 6 months.

The best approach anticipated the onset of the high transmission season 2019 in June in 2 districts, July in 46 districts, August in 21 districts and September in 6 districts. Using this approach over the 2014-2019 period would have led to changing the timing of SMC interventions in 36 health districts and would have prevented 43,819 cases, 1,943 hospitalisations and 70 deaths in children under 5 years. The additional cost of using our proposed approach is less than $5 \%$ of the current approach.

Conclusion Adapting the timing of SMC interventions using our proposed approach would improve the prevention of malaria cases, hospitalisations, and deaths for a reasonable additional cost.

\section{Introduction}

In 2019, 272,000 deaths attributable to malaria occurred in children under 5 years and $94 \%$ of global deaths were recorded in Africa [1]. According to the Local Health Information System (SLIS), the number of hospital deaths attributable to malaria in Mali was 1,454 out of 2,884,837 confirmed cases in 2020 [2]. Moreover, the 2018 Mali Demographic and Health Survey (DHS) found a mortality of 101 per 1,000 children [3], a figure higher than the average mortality of 76 per 1,000 children reported by the World Bank for the Sub-Saharan Africa region in 2019 [4].

The World Health Organisation (WHO) technical guidelines for malaria control recommend the implementation of targeted interventions in endemic countries [5]. Targeting consists of deploying the most relevant interventions based on local epidemiological context to make better use of available financial resources [6, 7]. Recommended interventions include community-based diagnostic and treatment, chemoprevention for children under 5 years and pregnant women, vector control using insecticide-treated 
nets, indoor residual spraying and larviciding $[5,8]$. In low prevalence countries (i.e., malaria prevalence of less than $1 \%$ ), mass drug administration is recommended to reduce asymptomatic carriage and to control epidemics [9]. Epidemiological surveillance is performed at all stages of malaria control (clinical, parasitological, entomological and molecular) to determine the timing of outbreaks, to detect epidemic resurgence and to track the development of parasite and mosquito resistance, with a view to adapt the timing of interventions and checking the progress made [5]. Between 2010-2017, targeted control interventions helped to reduce the global incidence of malaria by more than $40 \%$ [1].

Seasonal malaria chemoprevention (SMC) is currently one of the most efficient interventions to reduce both uncomplicated and severe morbidity ( $>80 \%$ reduction in clinical trials) and mortality ( $61 \%$ reduction in a comparison between districts implementing SMC or not) [10,11], which consists of the monthly administration of antimalarial drugs (Sulfadoxine-pyrimethamine and Amodiaquine) to children under 5 years during the high malaria transmission season [12]. Another study found that deaths and hospitalisations attributable to malaria were $44 \%$ and $61 \%$ lower, respectively, in health districts where SMC was implemented compared with those where it was not [13]. In Mali, SMC was adopted in 2012 and is currently implemented in all health districts since 2016, with 4 rounds of treatment at fixed dates from July to October country-wide corresponding to the high transmission season.

At the national level, however, no decline in malaria incidence was observed in children under 5 years between 2018 and 2020, even though the effectiveness of control interventions did not seem to be compromised by parasite resistance [1]. This suggests a need for improving malaria control in Mali, including by adapting the timing of SMC interventions to that of malaria transmission.

usually, the number of malaria cases increases after the onset of the rainy season, with a lag that corresponds to the delayed impact on transmission of the increase in mosquito activity $[14,15]$ after aestivation [16, 17]. In Mali, this lag ranges from 5 to 18 weeks depending on the eco-climatic zone [14, 15]. At the end of the rainy season, transmission decreases in most areas but can persist for several. weeks in flooded areas due to the lasting presence of humid zones, aquatic vegetation, and the malaria vector species Anopheles funestus following Anopheles gambiae [18]. In the Sahelian zone of Mali, where the rainy season lasts from July to November and the flooding season from November to February, a first peak in malaria cases is observed in September and a second peak in December [18], suggesting that malaria transmission can continue until December or January.

Currently, the Mali National Malaria Control Program (NMCP) implements SMC interventions based on historical national data on malaria incidence or prevalence [19]. This approach, however, does not account for the spatio-temporal heterogeneity of malaria transmission at the health district level, a heterogeneity that depends on a combination of meteorological, socio-economic and climatic factors. While the spatio-temporal heterogeneity of malaria transmission has been explored in specific regions of Mali [20-22], it has yet to be described at the scale of the entire country.

Importantly, SMC has proven to be a cost-effective intervention. In Mali, the average cost per child per visit was $€ 1,12$ (745 FCFA) in 2012 [23] and was reduced to 0.73€ (425 FCFA) in 2014 [24]. Given the limited 
available resources, the efficacy of SMC must be continually improved by adapting the timing of interventions to the spatio-temporal heterogeneity of malaria transmission.

This study aims to analyse available surveillance data at district level to propose local adaptation of SMC timing and number of rounds in Mali. Our primary objective was to select the best approach for anticipation of the onset of the high transmission season in the different health districts of Mali based on epidemiological surveillance and rainfall data. Our secondary objective was to evaluate the number of malaria cases, hospitalisations, and deaths in children under 5 years that could be prevented in Mali using the selected approach as well as the additional cost associated.

\section{Method}

Study site

Mali is a continental landlocked country spreading over 1,241,248 $\mathrm{km}^{2}$ with an estimated 22-million population in 2021 (updated from 2009 national census) [25].

Mali spread across 4 ecoclimatic zones: the Saharan zone in the north (annual rainfall of less than $200 \mathrm{~m}$ ), the vast Sahelian zone in the centre (annual rainfall of up to $800 \mathrm{~mm}$ ), the Sudanese-Sahelian zone in the southeast (annual rainfall of $1,000 \mathrm{~mm}$ ) and the Sudanese-Guinean zone in the extreme south (annual rainfall of more than 1,000 mm). There are two seasons in Mali: the dry season from November to March and the rainy season from April to October. Beginning around April or May, the rains come in the form of intermittent thunderstorms.

Mali is divided into 75 health districts. Each health district has its own hospital, which provides primary care and conducts epidemiological surveillance.

Data and data source

Malaria data

In Mali, confirmed malaria cases are recorded weekly at the health district level via the epidemiological surveillance system and then reported to the NMCP using DHIS2. Malaria cases are confirmed using rapid diagnostic test or the thick blood smears. We collected weekly aggregated data on confirmed malaria cases for the 75 health districts of Mali for the 2014-2019 period. No personal data were collected.

Rainfall data

Weekly rainfall data by health district were extracted from the Climate Hazards Group InfraRed Precipitation with Station data (CHIRPS) database via the Google Earth engine interface [26, 27] for the 2014-2019 period.

Population data

Population by health district was calculated for the 2014-2019 period by projecting population data obtained from the $2009 \mathrm{RGPH}$. 
Intervention cost data

Data on the cost of SMC interventions were obtained from the NMCP.

Data validation

The NMCP conducts periodic reviews of surveillance data as part of quality improvement of malaria data.

\section{Data analysis}

The first part of the analysis determined the median onset of the rainy season, the median onset of the high transmission season, the median lag between these two events and the median duration of the high transmission season in each health district for the 2014-2019 period.

The median onset of the rainy season in each health district for the 2014-2019 period was determined using weekly rainfall data. Adapting the definition proposed by Sivakumar and Balme [28], we defined the onset of the rainy season as the week after 1 April when rainfall reached 20 millimetres.

The median onset and median duration of the high transmission season in each health district for the 20142019 period were determined by performing a change point analysis of weekly incidence data [29, 30]. For each health district, incidence per 1,000 persons was calculated by dividing the number of weekly cases by population $\times$ week.

The lag between the median onset of the rainy season and the median onset of the high transmission season reflected the delayed impact on malaria transmission of the increase in mosquito activity after aestivation. It was calculated as follows (Equation 1):

$$
\text { Medainlag = medianonsetofhightransmissionseason }- \text { medianonsetofrainyseason(1) }
$$

Two anticipating approaches were evaluated. The first approach, App-A, anticipated the onset of the high transmission season in 2019 using median rainfall data and median lag data for the 2014-2018 period.

The second approach B, App-B, anticipated the onset of the high transmission season in 2019 using observational rainfall data for 2019 and median lag data for the 2014-2018 period.

The two approaches were tested by calculating the difference in weeks between the observed and anticipated onset of the high transmission season in 2019. A difference between -2 and +2 weeks was considered as acceptable. For each health district $i$ :

Error $_{i}=$ observedonset $_{i}$ ofhightransmissionseason - anticipatedonset $_{i}$ ofhightransmissionseason 2

The onset of the high transmission season helped to determine the start date of SMC interventions in each health district. The duration of the high transmission season helped to determine the number of rounds of SMC needed in each health district. 
Incidence data were presented in a box and whisker format. Health districts with an absence of seasonality and/or a low seasonal transmission were identified based on incidence figures and the results of the change point analysis.

The second part of the analysis determined the number of malaria cases, hospitalisations, and deaths in children under 5 years that could have been prevented using the best of the two anticipative approaches over the 2014-2019 period. The additional cost incurred by implementing SMC interventions using the best approach was evaluated.

Software and packages

All statistical analyses were performed using R software version 3.4 (R Development Core Team, R Foundation for Statistical Computing, Vienna, Austria) packages \{Changepoint\}\{ggplot\}.

\section{Results}

Anticipation of the onset of the high malaria transmission season

Over the 2014-2019 period, mean annual rainfall in Mali was $774 \mathrm{~mm}$, large variations are observed countrywide from $60 \mathrm{~mm}$ in the north (Taoudenit region in the Saharan zone) to 1,384 $\mathrm{mm}$ in the south (Sikasso region). The median onset of the rainy season ranged from W17 (April) in the south (Sikasso region) to W34 (August) in the north (Taoudenit region).

Mean annual malaria incidence over the 2014-2019 period was 90 cases per 1,000 persons year, ranging from 1 case per 1,000 persons year (Taoudenit region) to 285 cases per 1,000 persons year (Sikasso and Koulikoro regions). The median onset of the high transmission season ranged from W25 (June) to W40 (October) depending on the health district.

The median lag between the onset of the rainy season and the onset of the high transmission season ranged from 5 to 12 weeks depending on the health district.

Using the first approach (App-A), the anticipated onset of the high transmission season in 2019 ranged from W23 (June) to W40 (September). This anticipated onset was June in 2 health districts, July in 46 health districts, August in 21 health districts and September in 6 health districts (figure 1 Panel a).

Using the second approach (App-B), the anticipated onset of the high transmission season in 2019 ranged from W24 (June) to W41 (September). This anticipated onset was June in 1 health districts, July in 43 health districts, August in 15 health districts and September in 16 health districts (figure 1 Panel b).

The anticipated onset of the high transmission season in 2019 was between the 1st and 3rd quartile of the observed onset for $95 \%$ of health districts using App-A and for $68 \%$ of health districts using App-B. 
Table 1

Comparison of observed data and anticipation approaches

\begin{tabular}{|llll|}
\hline Month of high transmission season onset & Observed in 2019 & App-A & App-B \\
\hline May & 4 & 2 & 1 \\
\hline June & 36 & 40 & 43 \\
\hline July & 21 & 21 & 15 \\
\hline August & 14 & 12 & 10 \\
\hline September & 0 & 0 & 6 \\
\hline Median error & NA & 0 & -1 \\
\hline Number of districts with error up 2 weeks & NA & 3 & 25 \\
\hline
\end{tabular}

Both approaches anticipated the onset of the high transmission season with an error +/- 2 weeks. App-A presented the best prediction results: the median error was 0 weeks, with no error for 34 health districts (45\%) and an error of 2 weeks for 3 health districts (Ansongo, Sikasso and Niena) (4\%) (figure 1, Panel c, and Table 1). App-B had a median error of 1 week, with an error of 2 weeks for the health districts with strong epidemic potential, which are located mainly in the northern regions (Ménaka and Taoudenit regions) and in the District of Bamako (figure 1, Panel d and Table 1).

Duration of the high malaria transmission season

Over the 2014-2019 period, the mean duration of the high transmission season was 4 months. The median duration of the high transmission season ranged from 3 to 6 months (figure 2 Panel a). The high transmission season began between June and August and ended between October and February/March.

The seasonality of malaria transmission was usual in 73 health districts (97.33\%). It was bimodal in 8 health districts (Ansongo, Diré, Goundam, Gourma Rharous, Menaka, Niafunké, Timbuktu and Youwarou), all of them located along the Niger river (figure 2 Panel b). No seasonality was observed in the health districts of Tinessako, Tessalit and Tindermene (figure 2 panel c). In the 6 health districts of the Taoudenit region, seasonal transmission was very low, with a weekly incidence of less than 1 case per 1,000 persons week (figure 2 Panel d).

Based on our analysis, the current strategy of 4 rounds initiated between July and October is appropriate for $39 / 75$ health districts. The number of SMC rounds should be adapted to the transmission season duration in $36 / 75$ health districts: 20 should receive 5 rounds due to a longer high transmission season or to bimodal transmission; 7 should receive 3 rounds due to a shorter high transmission season. and 9 should suspend SMC interventions due to the absence of seasonality and/or a low seasonal transmission (figure 3 ).

Based on a unit cost per child of $0.73 €$, the overall cost of implementing SMC interventions in the 75 health districts using App-A would be 11,965,070€ compared to 11,404,705€ for the current approach. The additional cost incurred would be $560,365 €$, which represents less than $5 \%$ of the current cost. 


\section{Discussion}

Our study proposed an approach for anticipating the onset of the high transmission season in the different health districts of Mali using epidemiological surveillance and rainfall data with a view to adapting the timing and duration of SMC interventions. The heterogeneity of the rainy season onset (spreading over nearly 3 months from South to North Mali) combined to ecological gradient resulted in large heterogeneities in the onset and duration of the malaria transmission season. The current strategy appears to match most districts but could be adapted in 36/75 districts, yielding additional morbidity and mortality reductions (43,819 cases, 1,943 hospitalisations and 70 deaths in children under 5 years) at a minimal incremental cost $(560,365)$.

Studies conducted in other malaria endemic countries reported lags between the onset of the rainfall season and the onset of the high transmission season that are consistent with our results [18, 31-33]. Moreover, as in our study, rainfall in the Sahelian zone has been shown to vary considerably over time [20, 34]. Given this variability, some authors suggest using rainfall data over several years when planning malaria control interventions, as in App-A [35, 36]. This strategy, already used in the field of agriculture and has shown its efficacy in the Gourma zone of Mali [37, 38], was specifically recommended in a study conducted in the Sahelian zone of Niger (Zinder) for the epidemiological surveillance of malaria[39]. Insofar as it accounts for the high variability of rainfall over time, the anticipated approach proposed in our study (App- A) could contribute to improve malaria control in Mali.

The usual seasonality of malaria transmission in Mali consists of a period of low transmission followed by a period of high transmission. Since the high transmission season lasts 4 months on average, Mali is considered eligible for SMC interventions by the WHO [12]. However, our study indicated that the onset and duration of the high transmission season vary considerably between health districts; the high transmission season begins 1 or 2 months earlier in the Sahelian and Sudanese-Guinean zones than in the Saharan zone and its duration varied between 3 and 6 months depending on the health district. This finding highlighted the importance of adapting the timing of SMC interventions to the spatio-temporal heterogeneity of malaria transmission. In the Saharan zone several districts showed no seasonality and/or low seasonal malaria transmission (i.e., no cases for several weeks), indicating that they benefit little from SMC interventions. In these health districts epidemiological surveillance should be modified from weekly surveillance to daily surveillance and interventions should be performed on a case-by-case basis (case reacting interventions). Note that these health districts borders the Maghreb countries, which are malaria-free or have sporadic transmission [40].

In 2019, the District of Bamako was excluded from the SMC program based on the 2018 National Demographic and Health Survey which reported a low prevalence of malaria in children 3-59 months [3].This survey, however, was carried out during an SMC intervention, which may have biased the results. In our study, a high incidence of malaria was found in the general population of the District of Bamako, suggesting that it - or at the very least its peri-urban area [41] - should be reintegrated in the SMC program. Indeed, studies have shown that the persistence of malaria in the general population can lead to epidemic resurgence with severe cases in children [42,43]. Likewise, the absence of premunition in the population of health districts with low seasonal transmission has been found to increase the risk of epidemics [41]. 
Our analysis of the duration of the high transmission season showed that an average of 4 rounds of SMC was needed across all health districts of Mali. However, 5 rounds of SMC were required in health districts with a long rainy season and in those with bimodal transmission (these being located in flooded areas or next to dams). Interestingly, a study conducted in Ghana found that the malaria burden could be reduced by $50 \%$ if 5 or more rounds of SMC were implemented during the high transmission season [44].

The additional cost with adaptation is partly offset by the exclusion of very low incidence and non-seasonal health districts. Despite this additional cost, the unit cost in Mali remains similar to several endemic countries (figure 3) [45].

The study conducted on the cost of SMC shows a benefit in relation to the investment [46]. This cost can be improved by adapting the implementation of SMC to local transmission. The number of distribution days per round is 5 days in Mali, while other countries have been making it in 3-4 days since the beginning like Senegal, Burkina and Niger [45].

By adapting the implementation of SMC in terms of timing, duration, number of rounds and the number of days needed per round, SMC can become a still efficient malaria control intervention. Using App-A could help to adapt the timing of SMC interventions in health districts with an early onset and/or long duration of the high transmission season. Using this approach over the 2014-2019 period would have led to changing the timing of SMC interventions in 36 health districts and would have prevented 43,819 cases, 1,943 hospitalisations and 70 deaths in children under 5 years (figure 4).

The main limitation of our study is that we used weekly data and may failed to account for undiagnosed malaria cases or report failures. It should be noted, however, that the quality of malaria data in Mali has been considerably improved in recent years following the implementation of periodic reviews of epidemiological surveillance data by the NMCP.

Our results show that adapting the timing of SMC interventions in each health district using our proposed approach (App-A) could improve the malaria control strategy and reduce the malaria burden in Mali and other malaria endemic countries for a reasonable additional cost.

\section{Conclusion}

The study proposes a simple and effective anticipative approach for optimising SMC interventions in Mali based on epidemiological surveillance and rainfall data. This approach can be used to adapt the timing of SMC interventions to that of malaria transmission in each health district of Mali for a reasonable additional cost. It can also be extended to other African countries with similar climatic characteristics.

\section{Abbreviations}

SLIS

Local Health Information System

DHS

Demographic and Health Survey 
WHO

World Health Organisation

SMC

Seasonal chemoprevention

NMCP

National Malaria Control Program

$\mathrm{RGPH}$

General Population and Housing Census

CHIRPS

Climate Hazards Group InfraRed Precipitation with Station

\section{Declarations}

\section{Availability of data and materials}

The data and background maps are available on request.

\section{Consent to publish}

Not applicable.

\section{Acknowledgements}

We would like to thank the NMCP of Mali. We are also grateful to Mrs. Tounkara Aminata and M. Keita Nogomory, from the Epidemiological Surveillance Division of the General Directorate of Health and Public Hygiene of Mali, and to Mr. Pascal Dembélé, in charge of epidemiological surveillance at the NMCP of Mali.

\section{Authors' contributions}

OYM, PD and MM collected primary data; MC and JG designed the study; MC, JL and CSB conducted the field study coordinated by MC; MC and JG developed the statistical analysis plan with the participation of JL, IS and $\mathrm{MBC}$; MC carried out the statistical analysis under the supervision of JG; MC performed the mapping analysis with the participation of CSB and JL; MC, JG, AK, JL, VS, DT, SD, MM, ID, ND and CSB participated in the statistical analysis and validated the results; MC, IS, ND and JG drafted the manuscript; all authors read and approved the final manuscript.

\section{Conflicts of Interest:}

The authors declare no conflicts of interest. 


\section{Funding}

This work was supported by an ARTS grant from the French Research Institute for Development (IRD) and by the JEAI (Jeunes Equipes associated with the IRD) "Dynamique Spatio-temporelle de la Transmission du Paludisme dans les Environnements Changeants" (DynaSTEC). Technical support was provided by the nongovernmental organisation Prospective et Coopération.

\section{Ethics and consent}

Our study was authorized by the competent authority, the National Malaria Control Programme (number 042/MSDS-SG/PNLP, 14 January 2021), in accordance with Malian regulations on ethics and medical research.

\section{References}

1. World Health Organization. World Malaria report 2019. 2020. https://www.who.int/news-room/factsheets/detail/malaria. Accessed 22 Jul 2021.

2. DGSHP - Mali. Annuaire Statistique du Système Local d'Information Sanitaire du Mali 2020. 2018.

3. CPS/SSDSPF, Institut National de la Statistique (INSTAT), Centre d'Études et d'Information Statistiques (INFO-STAT), Bamako, Mali. Demographic and Health Survey (DHS) in Mali. 2018. 2019.

4. The World bank Data. Estimates developed by the UN Inter-agency Group for Child Mortality Estimation (UNICEF, WHO, World Bank. UN DESA Population Division). Mortality rate, under-5 (per 1,000 live births) Sub-Saharan Africa | Data. 2019. https://data.worldbank.org/indicator/SH.DYN.MORT? locations=ZG\&view=map. Accessed 22 Jul 2021.

5. World Health Organization. Global Technical Strategy for Malaria 2016-2030. 2015. https://www.who.int/malaria/publications/atoz/9789241564991/en/.

6. Dieng S, Michel P, Guindo A, Sallah K, Ba E-H, Cissé B, et al. Application of Functional Data Analysis to Identify Patterns of Malaria Incidence, to Guide Targeted Control Strategies. International Journal of Environmental Research Public Health. 2020;17:4168.

7. World Health Organization. High burden to high impact: A targeted malaria response.:8.

8. Guo-Ding Z, Jun C. Progress and challenges of global malaria elimination. Zhongguo Xue Xi Chong Bing Fang Zhi Za Zhi. 2019;31:19-22.

9. World Health Organization. Mass drug administration for falciparum malaria: a practical field manual. 2017;:112.

10. Dicko A, Diallo Al, Tembine I, Dicko Y, Dara N, Sidibe Y, et al. Intermittent preventive treatment of malaria provides substantial protection against malaria in children already protected by an insecticide-treated bednet in Mali: a randomised, double-blind, placebo-controlled trial. PLoS Med. 2011;8:e1000407.

11. Cissé B, Sokhna C, Boulanger D, Milet J, Bâ EH, Richardson K, et al. Seasonal intermittent preventive treatment with artesunate and sulfadoxine-pyrimethamine for prevention of malaria in Senegalese children: a randomised, placebo-controlled, double-blind trial. The Lancet. 2006;367:659-67. 
12. World Health Organization. Chimioprévention du paludisme saisonnier par l'administration de la Sulfadoxine pyrimethamine et l'amodiaqune: Guide de terrain. 2013.

13. Issiaka D, Barry A, Traore T, Diarra B, Cook D, Keita M, et al. Impact of seasonal malaria chemoprevention on hospital admissions and mortality in children under 5 years of age in Ouelessebougou, Mali. Malar J. 2020;19:103.

14. Sissoko MS, Sissoko K, Kamate B, Samake Y, Goita S, Dabo A, et al. Temporal dynamic of malaria in a suburban area along the Niger River. Malaria Journal. 2017;16.

15. Gaudart J, Touré O, Dessay N, Dicko A, lassane, Ranque S, Forest L, et al. Modelling malaria incidence with environmental dependency in a locality of Sudanese savannah area, Mali. Malaria Journal. 2009;8:61.

16. Tandina F, Doumbo O, Yaro AS, Traoré SF, Parola P, Robert V. Mosquitoes (Diptera: Culicidae) and mosquito-borne diseases in Mali, West Africa. Parasit Vectors. 2018;11:467.

17. Magombedze G, Ferguson NM, Ghani AC. A trade-off between dry season survival longevity and wet season high net reproduction can explain the persistence of Anopheles mosquitoes. Parasit Vectors. 2018;11:576.

18. Cissoko M, Sagara I, Sankaré MH, Dieng S, Guindo A, Doumbia Z, et al. Geo-Epidemiology of Malaria at the Health Area Level, Dire Health District, Mali, 2013-2017. Int J Environ Res Public Health. 2020;17.

19. MNCP Mali. Plan Stratégique National de lutte contre le paludisme du Mali 2018-2022, p:1-155. 2018, Mali. 2018.

20. Diouf I, Rodriguez-Fonseca B, Deme A, Caminade C, Morse AP, Cisse M, et al. Comparison of Malaria Simulations Driven by Meteorological Observations and Reanalysis Products in Senegal. Int J Environ Res Public Health. 2017;14.

21. Coulibaly D, Travassos MA, Tolo Y, Laurens MB, Kone AK, Traore K, et al. Spatio-Temporal Dynamics of Asymptomatic Malaria: Bridging the Gap Between Annual Malaria Resurgences in a Sahelian Environment. Am J Trop Med Hyg. 2017;97:1761-9.

22. Rouamba T, Nakanabo-Diallo S, Derra K, Rouamba E, Kazienga A, Inoue Y, et al. Socioeconomic and environmental factors associated with malaria hotspots in the Nanoro demographic surveillance area, Burkina Faso. BMC Public Health. 2019;19:249.

23. Médecins Sans Frontières. Note de synthèse du Projet: Chimioprevention du paludisme saisonnier (CPS) au Mali district sanitaire de Koutiala, Région de Sikasso. 2013.

24. Diawara H, Walker P, Cairns M, Steinhardt LC, Diawara F, Kamate B, et al. Cost-effectiveness of districtwide seasonal malaria chemoprevention when implemented through routine malaria control programme in Kita, Mali using fixed point distribution. Malar J. 2021;20:128.

25. INSTAT - MALI. Rencement General of population and habitat Mali 2009. http://www.instat-mali.org/. Accessed 10 Feb 2020.

26. Gorelick N, Hancher M, Dixon M, Ilyushchenko S, Thau D, Moore R. Google Earth Engine: Planetary-scale geospatial analysis for everyone. Remote Sens Environ. 2017;202:18-27.

27. Aybar C, Wu Q, Bautista L, Yali R, Barja A. rgee: An R package for interacting with Google Earth Engine. Journal of Open Source Software. 2020;5:2272. 
28. Marteau R, Sultan B, Moron V, Baron C, Traore S, Alhassane A. Démarrage de la saison des pluies et date de semis du mil dans le sud-ouest du Niger. Actes du XXIlle colloque de l'association internationale de climatologie; 2010.

29. Zhang NR, Siegmund DO. A modified Bayes information criterion with applications to the analysis of comparative genomic hybridization data. Biometrics. 2007;63:22-32.

30. Chen J, Gupta AK. Parametric Statistical Change Point Analysis: With Applications to Genetics, Medicine, and Finance. 2nd edition. Birkhäuser Basel; 2012.

31. Coulibaly D, Rebaudet S, Travassos M, Tolo Y, Laurens M, Kone AK, et al. Spatio-temporal analysis of malaria within a transmission season in Bandiagara, Mali. Malaria Journal. 2013;12:82.

32. Faye $\mathrm{O}$, Gaye $\mathrm{O}$, Konaté L, Molez JF, Feller-Dansokho E, Hervé JP. Prediction and prevention of malaria epidemics in the valley of the Senegal River. Sante. 1998;8:347-52.

33. Steinig S, Harlaß J, Park W, Latif M. Sahel rainfall strength and onset improvements due to more realistic Atlantic cold tongue development in a climate model. Sci Rep. 2018;8.

34. J M. Origin of malaria epidemics on the plateaus of Madagascar and the mountains of east and south Africa. Bull Soc Pathol Exot. 1998;91:64-6.

35. Ateba FF, Sagara I, Sogoba N, Touré M, Konaté D, Diawara SI, et al. Spatio-Temporal Dynamic of Malaria Incidence: A Comparison of Two Ecological Zones in Mali. International Journal of Environmental Research Public Health. 2020;17:4698.

36. Touré Halimatou A, Kalifa T, Kyei-Baffour N. Assessment of changing trends of daily precipitation and temperature extremes in Bamako and Ségou in Mali from 1961- 2014. Weather Climate Extremes. 2017;18:8-16.

37. Frappart F, Hiernaux P, Guichard F, Mougin E, Kergoat L, Arjounin M, et al. Rainfall regime across the Sahel band in the Gourma region, Mali. J Hydrol. 2009;375:128-42.

38. Mougin E, Hiernaux P, Kergoat L, Grippa M, de Rosnay P, Timouk F, et al. The AMMA-CATCH Gourma observatory site in Mali: Relating climatic variations to changes in vegetation, surface hydrology, fluxes and natural resources. J Hydrol. 2009;375:14-33.

39. Julvez J, Mouchet J, Michault A, Fouta A, Hamidine M. The progress of malaria in sahelian eastern Niger. An ecological disaster zone. Bull Soc Pathol Exot. 1997;90:101-4.

40. Ba O, Ouldabdallahi M, Koïta M, Sy O, Dahdi SA. Epidemiology of malaria and elimination prospects in Maghreb Countries. Tunis Med. 2018;96:590-8.

41. Cot S, Matra R, Rabarijaona L, Robert V, Raharimalala L, Raveloson A, et al. Evidence of an urban, local transmission of malaria in Antananarivo, Madagascar. Med Trop (Mars). 2006;66:143-8.

42. Kouriba B, Diarra AB, Douyon I, Diabaté DT, Kamissoko F, Guitteye H, et al. P. falciparum malaria prevalence among blood donors in Bamako, Mali. Transfus Clin Biol. 2017;24:62-7.

43. Gaye O, Faye O, Ndir O, Feller-Dansokho E, Faye O, Dieng Y, et al. Malaria in an urban environment: the case of the city of Rufisque in Senegal. Dakar Med. 1997;42:54-8.

44. Tagbor H, Antwi GD, Acheampong PR, Plange CB, Chandramohan D, Cairns M. Seasonal malaria chemoprevention in an area of extended seasonal transmission in Ashanti, Ghana: an individually randomised clinical trial. Tropical Med Int Health. 2016;21:224-35. 
45. ACCESS-SMC Partnership. Effectiveness of seasonal malaria chemoprevention at scale in west and central Africa: an observational study. Lancet. 2020;396:1829-40.

46. Cairns M, Ceesay SJ, Sagara I, Zongo I, Kessely H, Gamougam K, et al. Effectiveness of seasonal malaria chemoprevention (SMC) treatments when SMC is implemented at scale: Case-control studies in 5 countries. PLOS Medicine. 2021;18:e1003727.

\section{Figures}

a

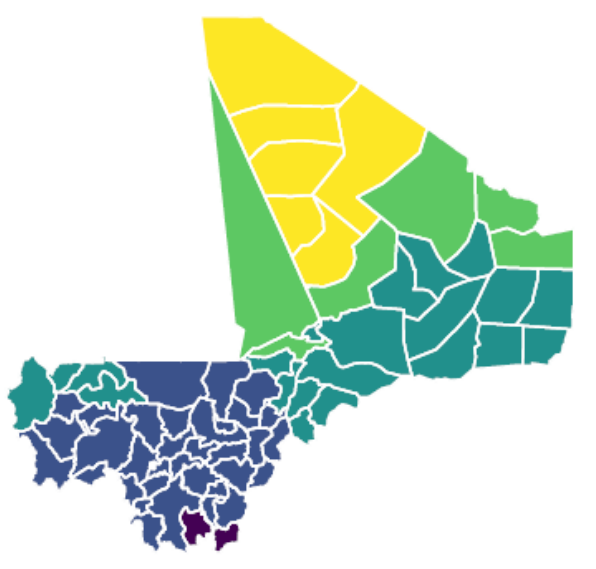

W23-W26 W27-W31 W32-W35 W36-W39 W40-W41
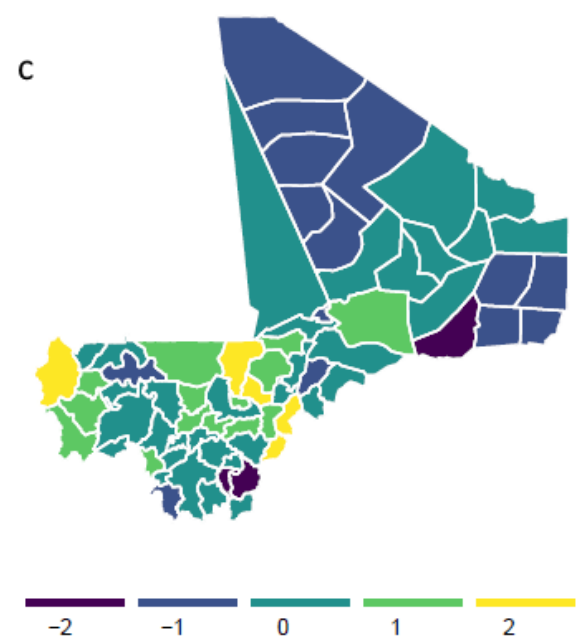

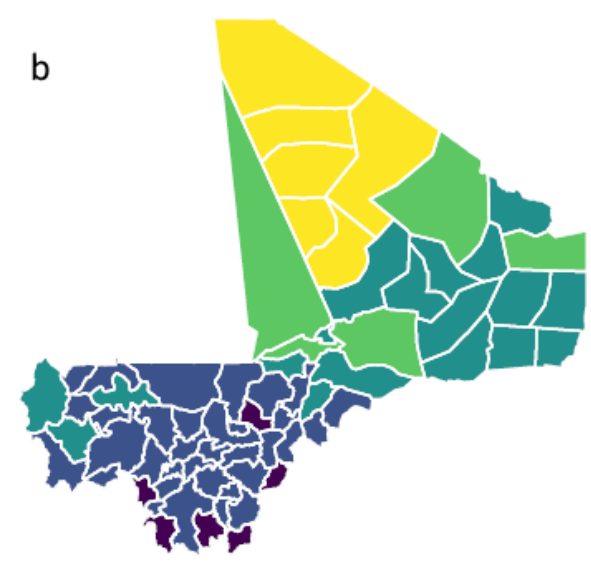

W24-W27 W28-W32 W33-W36 W37-W40 W41-W42

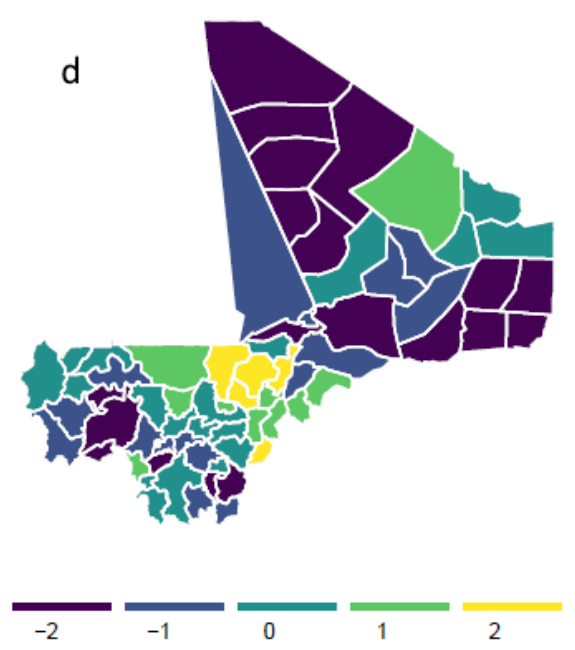

Figure 1

Two approaches for anticipating the onset of the high transmission season in 2019: App-A, based on median rainfall data and median lag data for the 2014-2018 period (Panel a); App-B, based on observational rainfall data for 2019 and median lag data for the 2014-2018 period (Panel b). The colour scales represent the onset week (W). Maps showing prediction errors in weeks using App-A (Panel c) and App-B (Panel d). The colour scales represent the error value. 


\section{Figure 2}

Duration and seasonality of malaria transmission in 4 particular health districts: bimodal seasonality (Panel a); usual seasonality (from July to December) (Panel b); absence of seasonality (Panel c); low seasonal transmission (Panel d).

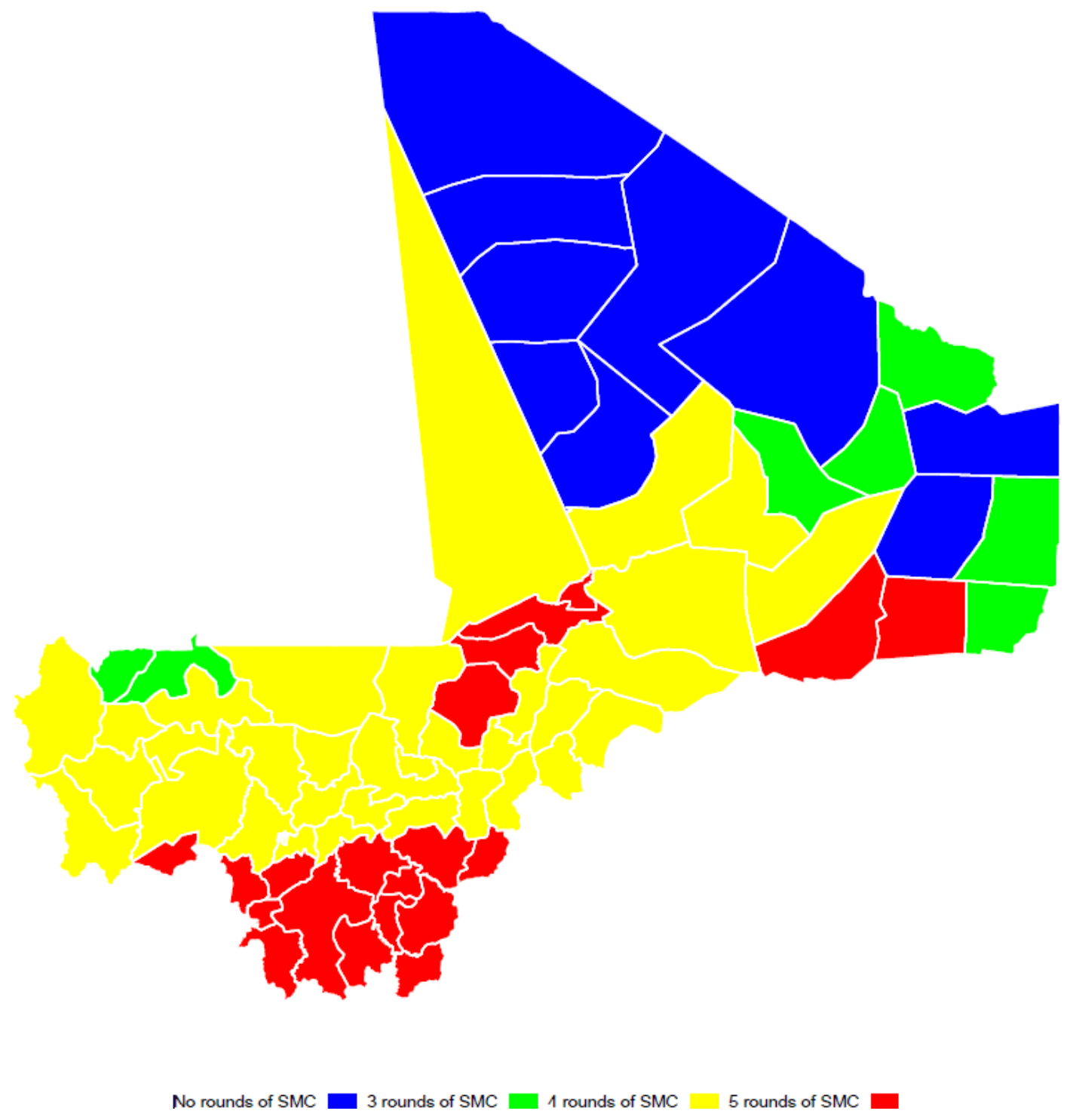

Figure 3

Number of rounds of seasonal chemoprevention (SMC) needed in each health district based on the duration of the high transmission season. The colour scale represents the number of estimated SMC rounds. 
a

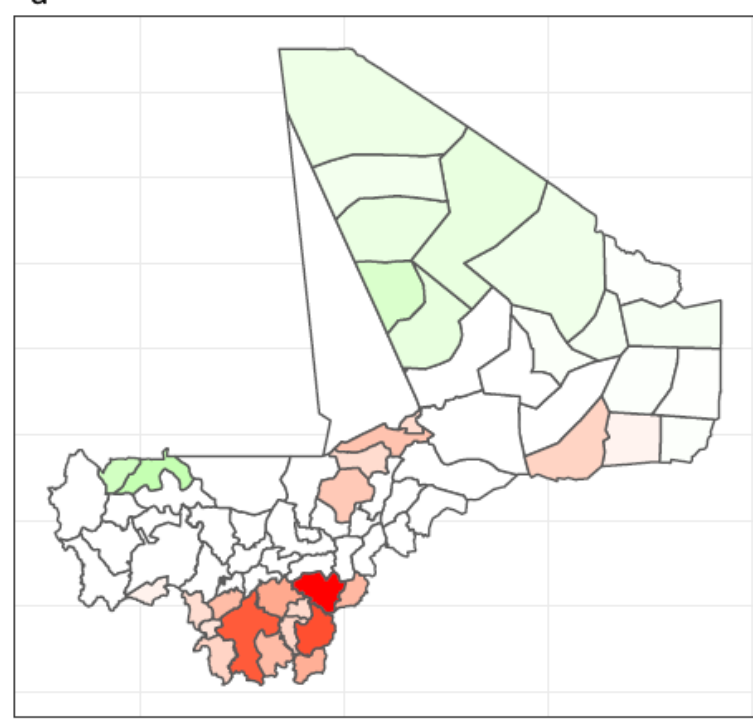

b

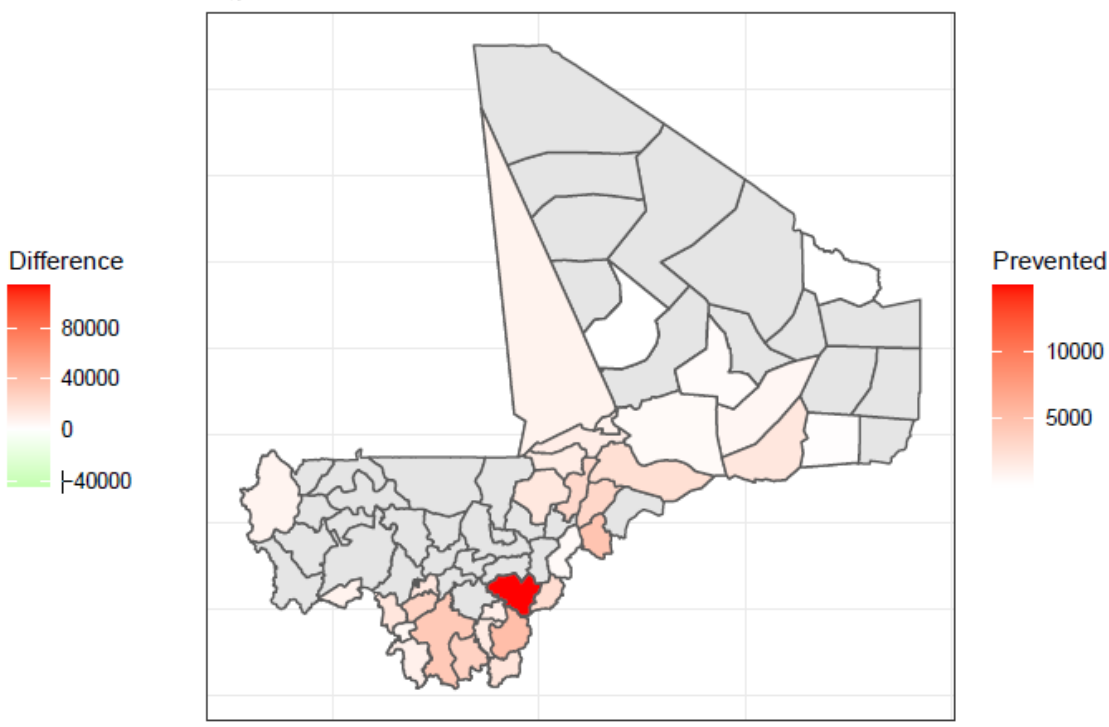

\section{Figure 4}

Additional costs of the adapted SMC by health district (Panel a). The color scale represents the differences between the observed costs (national SMC strategy) and the estimated cost (adapted SMC strategy); Potential preventive cases due to the adapted SMC (Panel b). The color scale represents the estimated number of cases that could be prevented by the adapted SMC strategy. Grey: no additional prevention.

\section{Supplementary Files}

This is a list of supplementary files associated with this preprint. Click to download.

- GraphicalAbstract.docx 